\title{
Does a big bazooka matter? Quantitative easing policies and exchange rates
}

\author{
By Luca Dedola, Georgios Georgiadis, Johannes Gräb and Arnaud Meh[[1]
}

What does quantitative easing $(\mathrm{QE})$ really mean for the exchange rate? This article explains how the relevant effects can be estimated using a statistical methodology derived from theory. The results suggest that QE has large and persistent effects on the USD/EUR exchange rate, mainly through shifts in exchange rate risk and short-term interest rates between the two currencies. Changes in expectations about the future monetary policy stance, reflecting the "signalling channel" of monetary policy, also affect how the USD/EUR exchange rate responds to QE.

\section{Introduction}

Since the onset of the global financial crisis in 2008, central banks around the world have rolled out a broad array of quantitative easing (QE) measures to ramp up their policy toolkits. This resulted in dramatic expansions of their balance sheets. The coronavirus (COVID-19) crisis has breathed new life into the argument that QE has become an essential monetary policy tool. On 18 March 2020 the ECB launched a $€ 750$ billion Pandemic Emergency Purchase Programme (PEPP), covering public and private securities, to soften the economic blow of the pandemic. Similarly, on 23 March 2020, the Federal Reserve System (the "Fed") announced that it would purchase unlimited amounts of US Treasury and mortgage-backed securities. Many other central banks, in advanced economies and emerging markets alike, have taken similar QE measures. ${ }^{[2]}$

A large literature has tried to assess the effects of QE, including how it affects the exchange rate. Specifically, the exchange rate has been centre stage in both the academic and policy debates about QE's effectiveness, transmission channels and spillovers (see, for example Rajan, 2013; Bernanke, 2015; Powell, 2018). While the ECB policy does not target the exchange rate itself, the exchange rate channel is an important part of the monetary policy transmission mechanism. So the exchange rate nonetheless plays an important role in achieving the ECB's actual objective of price stability over the medium term. Improving our understanding of the effects of QE on the exchange rate is therefore a central issue for monetary policy.

A recent study by Dedola, Georgiadis, Gräb and Mehl (2020) suggests that QE measures taken by either the ECB or the Fed have large and persistent effects on the USD/EUR exchange rate. The exchange rate effects of QE materialise mainly through shifting exchange rate risk (currency "risk premia"). To a lesser extent, they also arise through shifts in limits to arbitrage in foreign exchange markets, as well as the signalling channel, in other words through changes in expectations about the future monetary policy stance.

\section{Evidence of QE affecting the USD/EUR exchange rate and of its transmission channels}

To see why QE measures are thought to have potentially powerful effects on the exchange rate, you only have to look at how closely the USD/EUR exchange rate correlates with the relative sizes of the ECB's and 
the Fed's balance sheets (see Chart 1, where a fall in the exchange rate in the bottom panel denotes a euro depreciation).

In particular, when one central bank's balance sheet expands relative to the other's after the announcement of QE measures (shown as vertical lines on Chart 1), this has tended to be followed by a depreciation of the corresponding currency. These correlations of course tell us nothing about causality, and cannot be relied on to gauge the effectiveness or transmission channels of QE or to calibrate structural models to this end.

To address these limitations, Dedola, Georgiadis, Gräb and Mehl (2020) estimate the effects of QE on the exchange rate. They focus on time horizons that are relevant for policymakers and for informing structural models, and they explore the transmission channels through which the effects materialise over time.

In line with the monetary theory of the exchange rate as a relative price, they consider the size of the ECB's balance sheet relative to that of the Fed. They derive a regression equation based on standard theoretical asset pricing models, according to which the exchange rate today is determined by current and future expected fundamentals. In order to disentangle causal effects from simple correlations, they use announcements of QE measures to instrument future changes in the relative central bank balance sheet their proxy for QE shocks. In turn, they estimate the effects over time of these exogenous relative balance sheet changes on the USD/EUR exchange rate - and other relevant asset prices - using statistical methods known as "local projections with external instruments" (Jorda et al., 2015; Ramey and Zubairy, 2018). Such methods are particularly well suited to measuring the dynamic effects of QE on exchange rates over short and medium-term horizons. A particularly appealing feature of the paper's approach is that it yields estimates of an elasticity that measures the change in the exchange rate implied by a QE measure that changes the relative central bank balance sheet by a given magnitude. This elasticity can be used to gauge the effect of the QE measures taken since the outbreak of the COVID-19 pandemic.

\section{Chart 1}

Relative balance sheet, the USD/EUR exchange rate and QE announcements
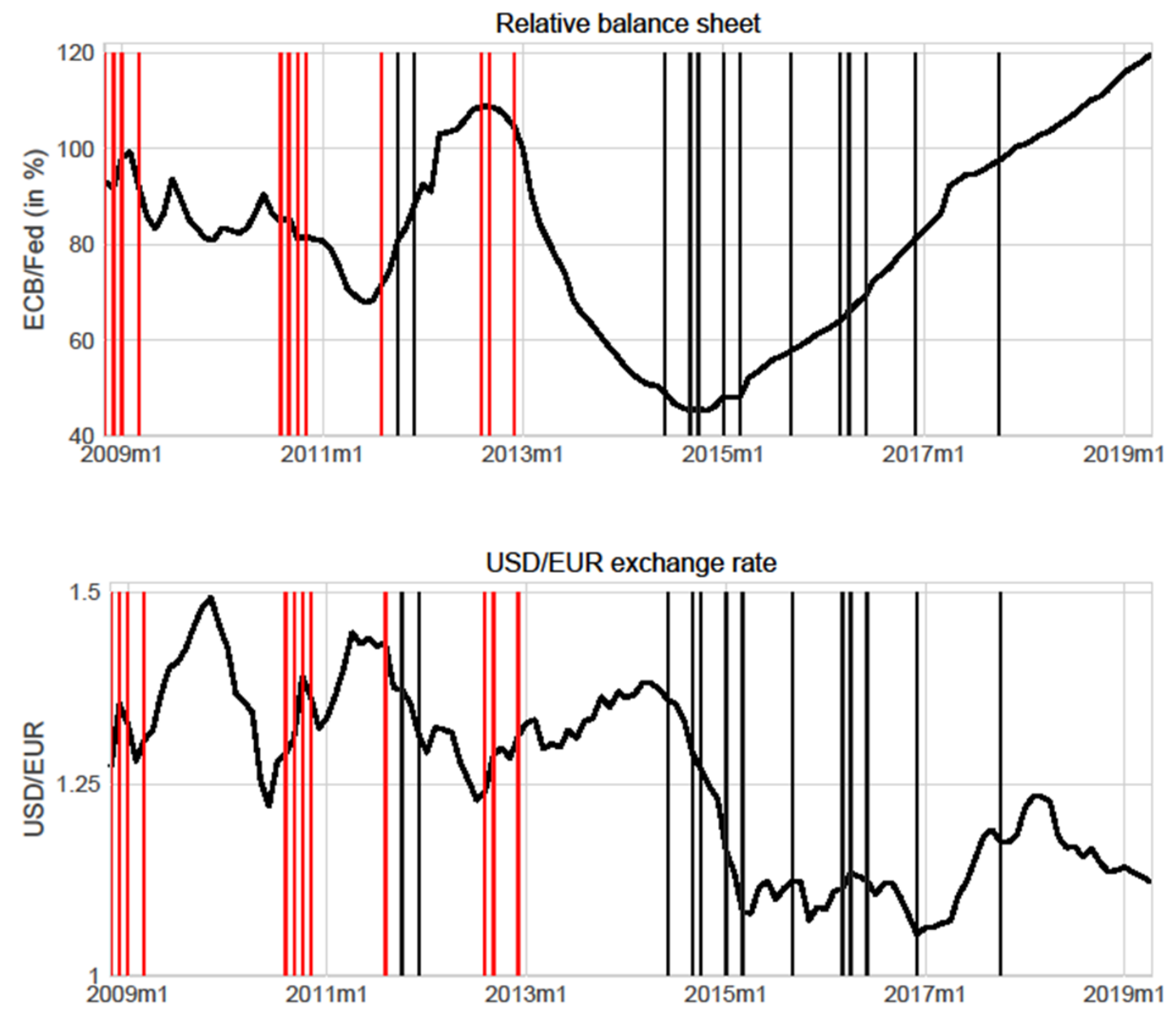
Note: The upper panel shows the evolution of the relative balance sheet of the ECB and the Fed (ECB/Fed in percentages). The bottom panel plots the USD/EUR exchange rate. Across both charts, the black (red) vertical lines indicate the dates of QE announcements by the ECB (Fed).

The findings of the study suggest that QE measures have had large and persistent effects on the exchange rate. The left-hand panel of Chart 2 shows the impulse response of the nominal US dollar-euro exchange rate to a relative QE shock that expands the ECB's balance sheet relative to that of the Fed by 1 percentage point over the following nine months. This is estimated from a sample of observations spanning from the global financial crisis in 2008 until the spring of 2019. The euro immediately depreciates against the US dollar once the QE shock has materialised, bottoming out at around $0.35 \%$ below the baseline after nine months. The depreciation is quite persistent and is statistically significant for up to 18 months.

This estimate of the effects of QE on the exchange rate remains fairly comparable with those for the effects of conventional monetary policy - it is broadly similar to the exchange rate effect of an unanticipated two-basis-point decline in one-year interest rates in the euro area relative to those in the United States. ${ }^{[3]}$

Overall, the estimates imply that a typical expansionary QE announcement by either the ECB or the Fed in the sample resulted in an increase in the relative balance sheet of about $20 \%$ over the next nine months, and, in turn, in a persistent exchange rate depreciation of around $7 \%$.

\section{Chart 2}

Impulse response to a relative ECB-Fed QE shock

\section{(percentages and months to "lift-off")}

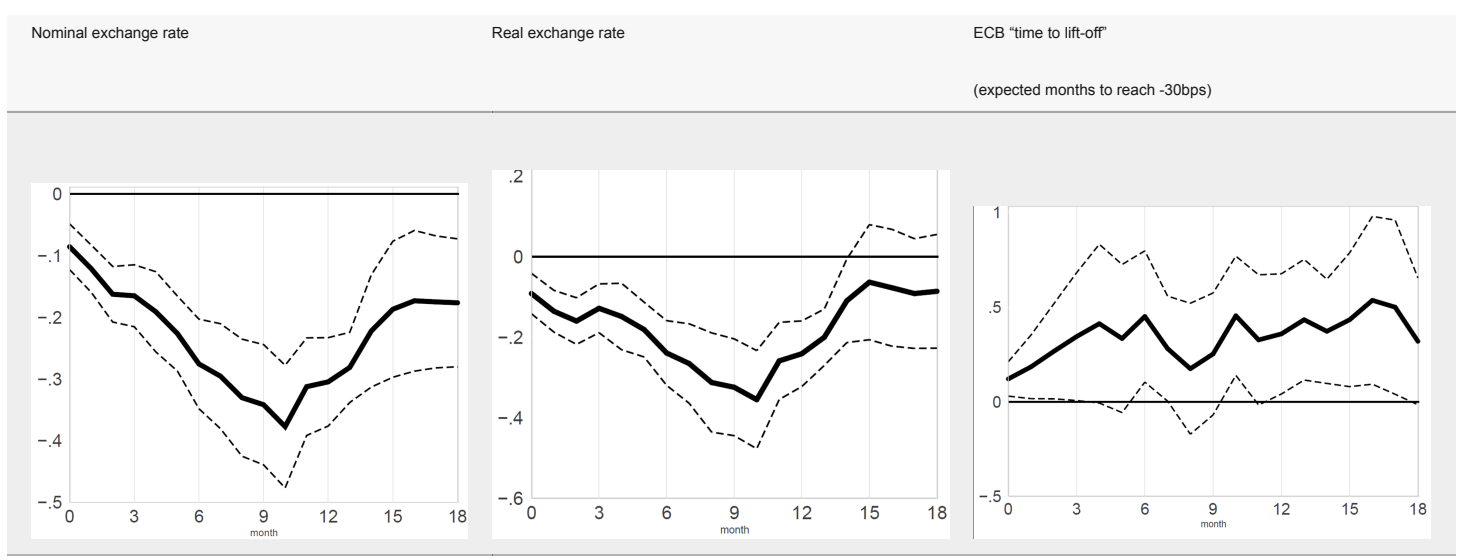

Note: The charts present estimates of the responses of the US dollar-euro nominal and real bilateral exchange rates to the relative QE shock that expands the ECB balance sheet relative to that of the Fed along with the response in the ECB's "time to lift-off". The estimates are obtained from the two-stage least squares local projection regression. The dotted lines represent $90 \%$ confidence bands based on robust standard errors.

Regarding the transmission channels, based on the forward solution to the uncovered interest rate parity equation, it is possible to break down the exchange rate response to a QE shock into contributions from short-term money market differentials, the cross-currency basis (or covered interest parity (CIP) deviations), the expected exchange rate and a residual component. In so doing, Dedola, Georgiadis, Gräb and Mehl (2020) find that a QE shock that expands the ECB's balance sheet relative to that of the Fed reduces the euro-dollar short-term money market rate differential (see the blue bars in Chart 3 ) ${ }^{[4]}$ The effects of QE on short-term interest rate differentials result in part from liquidity effects in money markets, and in part from expectations of further monetary policy accommodation over the medium term, the socalled "signalling" channel of QE (see Woodford, 2012). Also in support of the "signalling" channel, Dedola et al. find that a QE shock which expands the ECB's balance sheet relative to that of the Fed shifts markets' expectations regarding "time to lift-off", i.e. the first rate rise in the next tightening cycle of monetary policy, farther into the future (see the right-hand panel of Chart 2).

Nevertheless, the findings suggest that the lion's share of QE's impact on the exchange rate stems from "residual" deviations from uncovered interest parity (see Engel, 2016), as shown in Chart 3 (see the green 
bars). While this is a cover-all term for all unexplained deviations, it actually mirrors the behaviour of currency risk premia in the models by Gourinchas et al. (2019) and Greenwood et al. (2019). In these models, a balance sheet expansion by the central bank makes its currency more risky for intermediaries with limited risk-bearing capacity.

Finally, Dedola, Georgiadis, Gräb and Mehl (2020) document that an expansionary relative QE shock widens deviations from covered interest rate parity (CIP) as reflected in the cross-currency basis. Since CIP is a key arbitrage relation, QE shocks exacerbate limits to arbitrage in foreign exchange markets. However, the response of CIP deviations accounts only for a small fraction of the overall effects of QE on the exchange rate (see the red bars in Chart 3).

\section{Chart 3}

Breakdown of the exchange rate response to a relative ECB-Fed QE shock

(percentages)

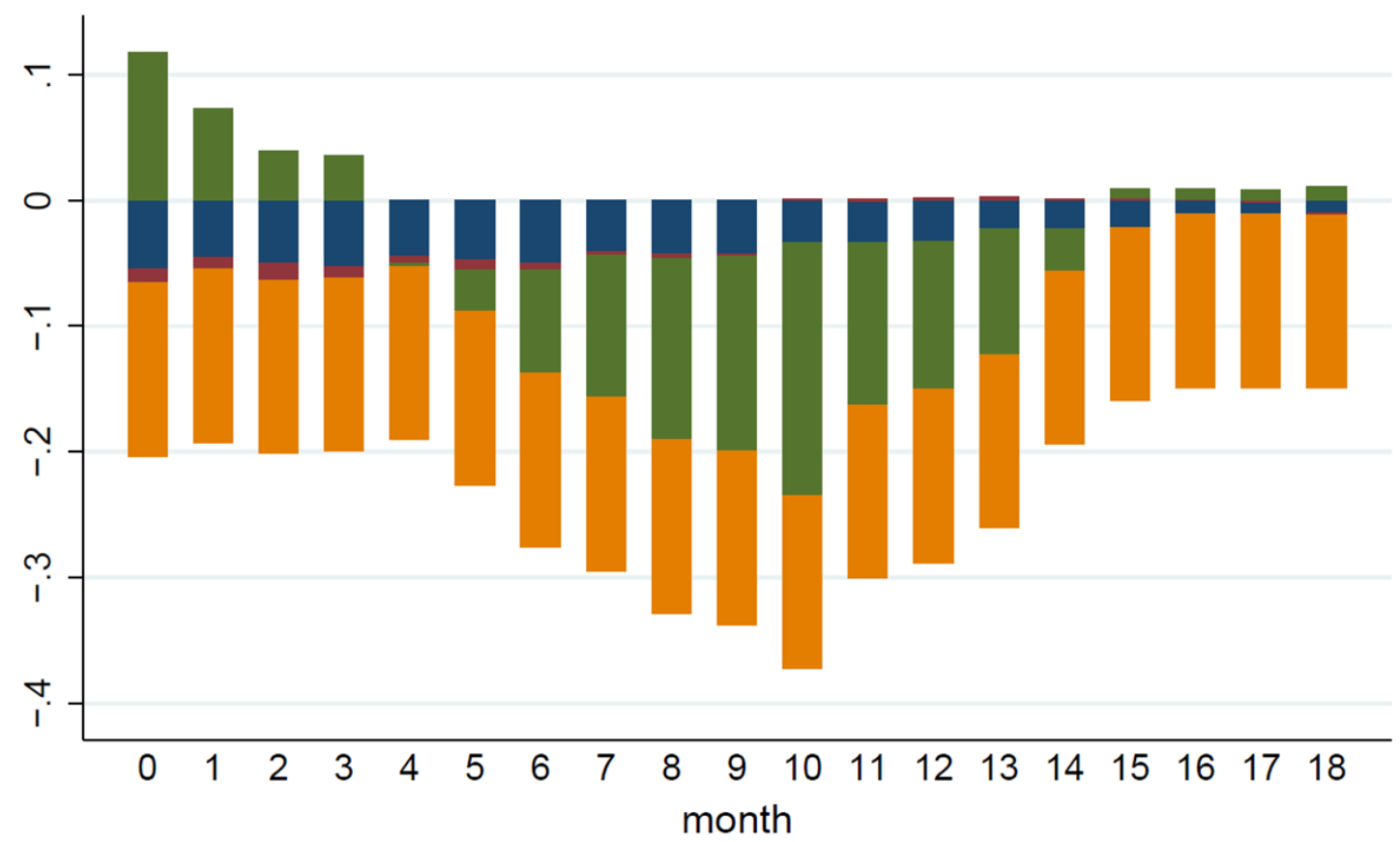

\begin{tabular}{|l|l|}
\hline 3m-MM-diff & $3 \mathrm{~m}$-CIP-deviation \\
\hline Risk premium & Expected exchange rate in $\mathrm{H}$ \\
\hline
\end{tabular}

Note: The figure presents the breakdown of the exchange rate response to a relative QE shock that increases the difference between the growth rates of the ECB's and the Fed's balance sheets by 1 percentage point into the UIP contributions accounted for by the response of the euro-dollar three-month money market rate differential ("3m-MM-diff"), the three-month CIP deviation ("3m-CIP-deviation") as well as the expected exchange rate at each forecast horizon (“Expected exchange rate in $\mathrm{H}$ "). The risk premium corresponds to the unexplained part, i.e. the residual.

\section{Conclusions and policy implications}

This article has shown that QE measures have large and persistent effects on the USD/EUR exchange rate. These are mainly transmitted through currency risk premia. But they also materialise through liquidity effects in money markets, signalling effects and, to a much smaller extent, limits to arbitrage in foreign exchange markets.

The estimates discussed in this article can be used to gauge the effect on the exchange rate of the measures taken by the ECB and the Fed since the outbreak of the COVID-19 pandemic. The Fed's balance sheet has expanded by 16 percentage points more than the ECB's since March 2020. ${ }^{[5]}$ Based on an elasticity estimate of 0.35 , this relative increase has led to an appreciation of the euro vis-à-vis the US dollar of almost $6 \%$ - more than half of the actual appreciation between March and September 2020 of around $10 \%$. 
These developments show how significant the exchange rate is as a transmission channel of monetary policy. As mentioned earlier, the ECB's monetary policy does not target the exchange rate itself. At the same time, in the current environment of heightened uncertainty, the ECB will carefully assess the implications of incoming information - including developments in the exchange rate - for the medium-term inflation outlook.

\section{References}

Bernanke, B. (2015), "Federal reserve policy in an international context", Speech at the $16^{\text {th }}$ Jacques Polak Annual Research Conference.

Bhattarai, S., Chatterjee, A. and Park, W.Y. (2018), "Effects of US quantitative easing on emerging market economies", Asian Development Bank Institute Working Paper Series, No. 803.

Ca' Zorzi, M., Dedola, L., Georgiadis, G., Jarociński, M., Stracca, L. and Strasser, G. (2020), "Monetary policy and its transmission in a globalised world", ECB Discussion Papers, No. 2407.

Dedola, L., Georgiadis, G., Gräb, J., and Mehl, A. (2020), “Does a big bazooka matter? Quantitative easing policies and exchange rates?" Journal of Monetary Economics (forthcoming).

Engel, C. (2016), “Exchange rates, interest rates, and the risk premium”, American Economic Review, No. 106, pp. 436-474.

Gourinchas, P.O., Ray, W. and Vayanos, D. (2019), "A preferred-habitat model of term premia and currency risk", mimeo.

Greenwood, R., Hanson, S., Stein, J. and Sunderam, A. (2019), "A quantity-driven theory of term premiums and exchange rates", mimeo.

Hartley, J. and Rebucci, A. (2020), "An event study of COVID-19 central bank quantitative easing in advanced and emerging economies”, NBER Working Papers, No. 27339.

Jorda, O., Schularick, M. and Taylor, A. (2015), "Betting the house", Journal of International Economics, No. 96, pp. 2-18.

Rajan, R. (2013), "A step in the dark: unconventional monetary policy after the crisis", Speech at the Andrew Crockett Memorial Lecture, BIS, Basel.

Powell, J. (2018), "Monetary policy influences on global financial conditions and international capital flows", Speech at the 8th High-level IMF/SNB Conference on the International Monetary System, Zurich.

Ramey, V., Zubairy, S. (2018), "Government spending multipliers in good times and in bad: evidence from U.S. historical data", Journal of Political Economy, No. 126, pp. 850-901.

Woodford, M. (2012), "Methods of policy accommodation at the interest-rate lower bound", Proceedings Economic Policy Symposium - Jackson Hole, pp. 185-288.

\footnotetext{
[1] The article was written by Luca Dedola (Senior Adviser, Directorate General Research, European Central Bank and CEPR), Georgios Georgiadis (Senior Economist, Directorate General International and European Relations, European Central Bank), Johannes Gräb (Team Lead, Directorate General International and European Relations, European Central Bank) and Arnaud Mehl (Adviser, Directorate General International and European Relations and CEPR). The authors gratefully acknowledge the comments of Alberto Martin and Zoë Sprokel. The views expressed here are those of the authors and do not necessarily represent the views of the European Central Bank or the Eurosystem.

[2] Hartley and Rebucci (2020) provide a survey of the QE measures introduced by central banks around the world since the outbreak of the COVID-19 pandemic.

[3] See Ca' Zorzi et al. (2020).

[4] CIP deviations refer to deviations from the standard arbitrage relation between spot exchange rates, exchange rate futures and interest rate differentials, while uncovered interest rate (UIP) deviations refer to actual changes in exchange rates not accounted for by interest rate differentials.

[5] We consider here the actual purchases of the Fed since 23 March 2020 and assume that there will be no further purchases until next year, which is broadly in line with the observation that the Fed's balance sheet has remained stable over the past two months. For the ECB we take into account both the $€ 750$ billion PEPP envelope of purchases announced on 18 March 2020 and its increase to $€ 1,350$ billion as announced on 4 June.
} 
Copyright 2020, European Central Bank 